\title{
POLITICAL PARTICIPATION AND VOLUNTEERING DURING THE COVID-19 PANDEMIC IN HUNGARY
}

\author{
DÁNIEL MiKeCZ, DÁNIEL OROSS ${ }^{1}$
}

\section{THE PROJECT'S OBJECTIVES}

The COVID-19 pandemic has had massive, global-scale impacts. For the realization of policy goals, the pandemic calls for citizen co-production. Since most policies are voluntary, levers for encouraging compliance with them oblige public servants to find ways to activate residents' civic sense of duty. Such efforts are likely to be more effective if they harness the popular legitimacy of intermediaries - from civic organizations to for-profit companies - that can exert normative pressure for compliance. With the aim of the management and reduction of health, economic risks, and damages, several initiatives have been organized in Hungary. Initiators included political parties, registered NGOs, companies and informal groups and communities.

In our research, we seek to answer the question to what extent the emergence of the COVID-19 pandemic has changed previous trends in Hungarian social and political participation. Is the participation of high-status people still typical, and has the role of online participation in the political participation of Hungarian society increased? Have new participants appeared or become identifiable?

\section{RESEARCH QUESTIONS/HYPOTHESES}

We suggest that the COVID-19 pandemic has increased the significance of

1 The authors are both Research Fellows at the Centre for Social Sciences, Institute for Political Science, Hungarian Academy of Sciences Centre of Excellence; e-mails: mikecz.daniel@tk.mta. hu, oross.daniel@tk.mta.hu 
those civil initiatives and democratic innovations that are online based. After a shock, civic organizations were able to adapt to the new situation and organize collective action online.

As several studies confirm, women are more exposed to the risks of the pandemic, as their everyday workload has increased significantly (Azcona, Bhatt and Love, 2021). Other studies have shown that the proportion of women and their participation in civil responses to global challenges is greater (Wahlström et al. 2019). Therefore, it is essential to examine the intertwined roles of women as agents both in climate movements and in pandemic-related networks. By interconnecting the COVID-19 responses with the climate movement, we can obtain broader insight into social reactions to crisis situations.

\section{SAMPLE CHARACTERISTICS, DATA COLLECTION, SURVEY}

Data were collected by the IDEA Institute from April 20-26, 2020 using a social-media-based questionnaire. The representativeness of the data was ensured by applying a quota to the data collection process, which was also supplemented by multi-weighted correction based on the latest available demographic data from the Hungarian Central Statistical Office. Furthermore, iterative weighting (raking) with other variables was also used. The result is that the study is representative of the adult population of Hungary in terms of gender, age, education, and type of settlement. The margin of error of the 2000 sample is at most $+/-2.2$ percentage points for the basic distributions. In weighting the data collection, the researchers also took into account how much time respondents spent and how active they were on Facebook, and the proportion of different social groups (by age group and gender) using social media.

The survey contained 27 questions. Four questions related to political participation in the last 12 months (signing petitions, attending lawful demonstrations, being active in civil society organizations, contacting politicians) and two to participation since the pandemic (signing petitions, and contacting politicians). The focal areas of the questionnaire were voluntary activities since the pandemic. We asked respondents if they had participated in one of the following activities: sewing face-masks, volunteering at healthcare institutions, helping with shopping, donating, transporting donations, participating in distance teaching from home, online caring for lonely people, sharing, and writing pandemic-related content on social media. We also asked who organizes these activities (friends, a Facebook group, a civil organization, 
a religious group, municipality, healthcare institution, or other state institution). A final question asked if the respondents had joined a Facebook group or movement that advocated staying at home.

\section{FIRST RESULTS}

With regard to the traditional and direct forms of political participation we examined, the data show a remarkably high level of activity. In addition, during the coronavirus pandemic, pandemic-related volunteering exceeded the level of voluntary commitment under normal circumstances. Hence, both political participation and volunteering have increased since the outbreak of the coronavirus.

\section{DATA ACCESS}

The database will be accessible from June 2021 at the repository of the Library of the Hungarian Academy of Sciences.

\section{REFERENCES}

Azcona, G.; Bhatt, A. and Love, K. (2021) Ipsos Survey Confirms That COVID-19 Is Intensifying Women'S Workload At Home. UN Women Data Hub. https://data.unwomen.org/features/ipsos-survey-confirms-covid-19intensifying-womens-workload-home, Accessed 13 January 2021.

Wahlström, Mattias, Piotr Kocyba, Michiel De Vydt and Joost de Moor (Eds.) (2019) Protest for a future: Composition, mobilization and motives of the participants in Fridays For Future climate protests on 15 March, 2019 in 13 European cities. https://protestinstitut.eu/wp-content/ uploads/2019/07/20190709_Protest-for-a-future_GCS-Descriptive-Report. pdf 
